\title{
Teaching Process Control Using The CSTH Model
}

\author{
Xiangshun $\mathrm{Li}^{*}$ and $\mathrm{Xu}$ Jiang \\ School of Automation Wuhan University of Technology Wuhan 430070, China \\ ${ }^{*}$ Corresponding author
}

\begin{abstract}
This paper discusses a case-based approach to teaching process control involving modeling, measuring, PID and cascade control methods. In the traditional process control teaching, there are some problems such as knowledge points are taught without any example or taught by different examples. which make student be passive to study, and it's difficult to setup the whole knowledge system. Case teaching is an efficient method to help students understand the principles of process control and get the ability to solve practical problem. CSTH model is presented for the case which involves several knowledge points of process control in this article.
\end{abstract}

Keywords- process control; continuous stirred tank heater; case teaching

\section{INTRODUCTION}

Process control has become increasingly important in the process industries as a consequence of global competition, rapidly changing economic conditions, and more stringent environment and safety regulations. Process control is also a critical concern in the development of more flexible and more complex processes for manufacturing high value-added products[1]. As one of the compulsory and specific courses in the major of automation, process control involves theoretical knowledge and mathematical background and even engineering models. A good control engineering course should be accompanied by hands-on experiments [2]. This teaching method is called case teaching. It's obvious that how difficult it is to learn the concepts involved in process control without real models. Case teaching has a long history in business, law, and medical education. In recent years, case study has also been used for science and engineering education. Cases can be used not only to teach scientific concepts and content, but also process skills and creative thinking, because many perfect cases are based on contemporary, and contentious engineering problems. Therefore, choosing a perfect case is the key to case teaching. The case used in this paper is the CSTH model. Continuous stirred tank heater is widely used and is important system in the process and chemical industries for efficient process and good quality product[3].

Teachers are exploring an effective method of teaching in recent years. Case teaching has attracted many teachers' attention. A demo program for teaching the transformation of random variable in the context of its PDF and mean value and variance[4]. A linearized state model of a synchronous generator is introduced as an effective tool for demonstrating the value of state space control system[5]. In [6], teaching material developed with MATLAB/simulink can be successfully replaced by equivalent material developed with
Scilab/Scicos. A teaching methodology which is based on "theory and practice, basic and promotion" according to the characteristic of the teaching contents[7]. A pedagogical tool for teaching fuzzy control is presented, which develop students' practices of fuzzy logic and fuzzy control[8]. The Quadruple-Tank process is designed to illustrate many concepts in linear and nonlinear multivariable control[2]. An experiment-based approach to teaching intelligent control methodologies for students has deepened students understanding and capability to implement intelligent control strategy in real-time environment[9].

In the literatures, knowledge points are usually taught without any example or taught by different examp les, which make knowledge difficult to understand. And it is hard for students to setup a whole theatrical architecture. Thus conventional teaching is not very efficient to improve creative and practical ability. To better educate undergraduates, CSTH model, which is a practical simulation platform, is selected to teaching different knowledge points.

This paper is organized as follows: In Section 2, the description of continuous stirred tank heater is presented. Section 3 presents the knowledge of instrument and PID control and cascade control and the steps of using the CSTH model to teach. Section 4 the results are concluded.

\section{PROCESS DESCRIPTION}

\section{A. The Continuous Stirred Tank Heater Description [10]}

The model presented in this paper comes from the Department of Chemical and Materials Engineering at the University of Alberta. In this stirred tank, hot and cold water are mixed, heated further using steam through a heating coil and drained from the tank through a long pipe. The configuration is shown in Fig 1. The CSTH is well mixed and therefore the temperature in the tank is assumed the same as the outflow temperature. The tank has a circular cross section with a volume of 81 and height of $50 \mathrm{~cm}$. 


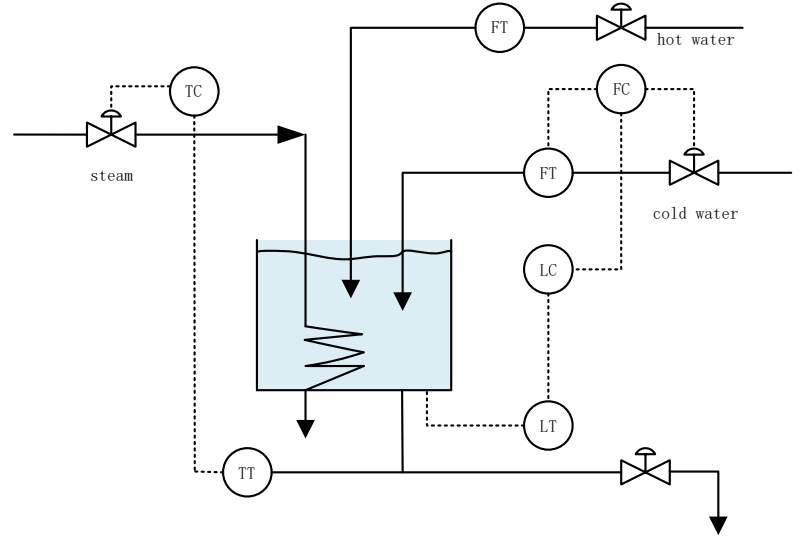

FIGURE I THE CONTINUOUS ST IRRED T ANK HEATER.

The cold and hot water (CW and HW) in the setup are pressurized with a pump to $60-80 \mathrm{psi}$, and the hot water boiler is heated by the university campus steam supply. The steam to the plant comes from the same central campus source. Control valves in the CSTH plant have pneumatic actuators using 3-15 psi compressed air supply, the seat and stem sets being chosen to suit the range of control. Flow instruments are orifice plates with differential pressure transmitters giving a nominal 4-20 $\mathrm{mA}$ output. The level instrument is also a differential pressure measurement. Finally, the temperature instrument is a type $\mathbf{J}$ metal sheathed thermocouple inserted into the outflow pipe with a Swagelock T-fitting.

\section{B. Simulation Model[10]}

It is difficult for some colleges to build a continuous stirred tank heater pilot plant similar to that of the University of Alberta. Therefore, simulation model teaching can be used. The simulation model of CSTH is shown in Fig 2.

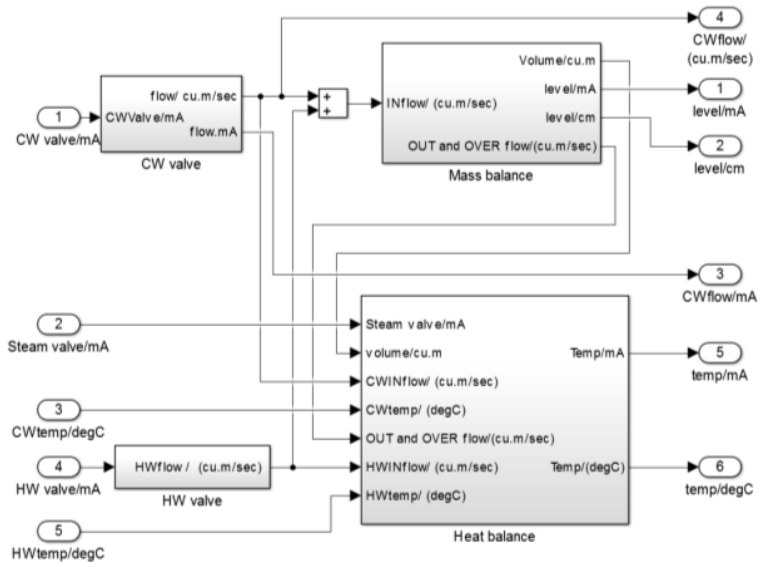

FIGURE II THE SIMULATION OF CSTH MODEL

\section{CSTH BASED STUDY}

The principles and simulation of the CSTH model have been introduced, and how to use CSTH to teach process control is now being discussed. Generally, CSTH can be used for theoretical modelling, PID tuning and cascade control.

\section{A. Theoretical Modelling}

Theoretical models of processes are based on conservation laws such as the balance of mass and energy which reflect movement, heat transfer, mass transfer and chemical reaction. Mass balance and energy conservation are presented in following.

\section{1) Mass balance}

The mass of water in the tank V can vary with time, and the exit flow rate is not necessarily equal to the sum of the inlet flow rates. An unsteady-state mass balance for the CSTH in Fig 1. has the form:

$$
\left\{\begin{array}{c}
\text { rate of accumulation } \\
\text { of mass in the tank }
\end{array}\right\}=\left\{\begin{array}{c}
\text { rate of } \\
\text { mass in }
\end{array}\right\}-\left\{\begin{array}{c}
\text { rate of } \\
\text { mass out }
\end{array}\right\}
$$

The mass of liquid in the tank can be expressed as the product of the water volume $\mathrm{V}$ and the density $\rho$. Consequently, the rate of mass accumulation is simply $\frac{\mathrm{d} V(x)}{\mathrm{dt}} \rho$, and (Eqs. 1) can be written as

$$
\frac{d V(x)}{d t} \rho=f_{c w} \rho+f_{h w} \rho-f_{\text {out }}(x) \rho
$$

where $\mathrm{x}$ is the level; $\mathrm{V}$ the volume of water; $f_{h w}$ is the hot water flow into the tank; $f_{\text {cw }}$ is the cold water flow into the tank; and $f_{\text {out }}$ is the outflow from the tank. Equation can be simplified as dynamic volumetric balance because the density of water $\rho$, is a constant.

$$
\frac{d V(x)}{d t}=f_{\text {cw }}+f_{h w}-f_{\text {out }}(x)
$$

\section{2) Energy conservation}

The general law of energy conservation can be expressed as

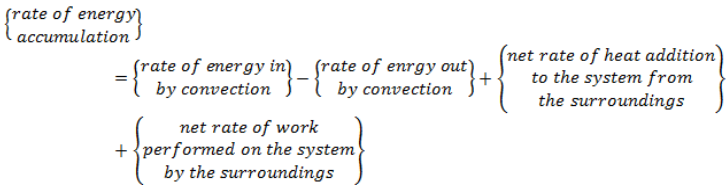

The general energy balance of CSTH can be written as

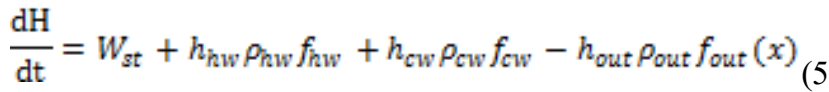

where $\mathrm{H}$ is the total enthalpy in the tank; $h_{h w}$ the specific enthalpy of hot water feed; $h_{c w}$ the specific enthalpy of cold water feed; $h_{\text {out }}$ the specific enthalpy of water leaving the 
tank; $P_{c w}$ the density of incoming cold water; $P_{i k w}$ the density of incoming hot water; $P_{\text {out }}$ the density of water leaving the tank; and $W_{\text {st }}$ the heat inflow from steam.

The additional introduction of $h_{\text {out }}, W_{\text {st }}$, $f_{\text {out }}$ is showed as follows:

- the specific enthalpy of water leaving the tank is

$$
h_{\text {out }}=\frac{H}{\rho_{\text {out }} V c_{p}\left(T-T_{\text {ref }}\right)}
$$

Where $c_{\mathrm{p}}$, and $\left(\mathrm{T}-T_{\text {ref }}\right)$ is as sumed to be constant.

- The heat transfer from the steam system depends on the steam valve setting. The relationship was determined empirically from steady state running at different steam valve settings since the heat exchange area and heat transfer coefficient could not be measured. The heat balance when the CSTH is in a steady state running with a cold water inflow only is:

$$
W_{\text {st }}=h_{\text {out }} P_{\text {out }} f_{\text {out }}-h_{\text {cw }} \rho_{c w} f_{\text {cw }}
$$

And $f_{\text {out }}=f_{c w}$ in steady state. The heat transferred at a given steam valve setting is not dependent on the temperature of the water in the tank.

- The relationship between the level in the tank and the flow through the outlet pipe is given by the equation

$$
f_{\text {out }}=\mathrm{m} \sqrt{(55+x)}+c
$$

where the parameters $\mathrm{m}$ and $\mathrm{c}$ can be determined by the slope and intercept of the straight line, $f_{\text {out }}$ plotted against the constructed quantity $\sqrt{(55+x)}$, where $\mathrm{x}$ is the level of the tank in $\mathrm{cm}[10,11]$.

\section{B. PID control}

PID controller consists of proportional, integral and derivative, which is the most widely used industrial controller. CSTH is a multivariable process, which can be controlled by PID controller when the other variables are set as constants and only one variable is left. For example, the flow rate of hot water and cold water can be set as constants so that the process conforms to the use of PID. The parallel form of the PID control algorithm is given by:

$$
\mathrm{u}(\mathrm{t})=K_{P}\left[e(t)+\frac{1}{T_{I}} \int_{0}^{t} e(t) d t+T_{D} \frac{d e(t)}{d t}\right]
$$

where $K_{P}, T_{I}$ and $T_{D}$ are, respectively, the control gain, integral time and derivative time. The functionalities are highlighted by the following.

- The proportional term:
(1) reduces (does not eliminate) offset

(2) speeds up response

(3) for oscillatory processes, makes closed-loop process more oscillatory

- The integral term::

(1) eliminate offset

(2) may make the transient response worse

- The derivative term:

(1) increasing the stability of the system

(2) reducing the overshoot

(3) improving the transient response

Effects of each of controllers $\mathrm{Kp}, \mathrm{Kd}$, and $\mathrm{Ki}$ on a closedloop systemare summarized in the table 1 .

TABLE I. EFFECT SOF INDEPENDENT P, I, AND D TUNING

\begin{tabular}{|c|c|c|c|c|}
\hline Cl response & Rise time & $\begin{array}{c}\text { Over- } \\
\text { shoot }\end{array}$ & $\begin{array}{c}\text { Setting } \\
\text { time }\end{array}$ & offset \\
\hline $\mathrm{kp}$ & decrease & $\begin{array}{c}\text { Incre- } \\
\text { ase }\end{array}$ & $\begin{array}{c}\text { Small } \\
\text { change }\end{array}$ & decrease \\
\hline $\mathrm{ki}$ & decrease & $\begin{array}{c}\text { Incre- } \\
\text { ase }\end{array}$ & increase & eliminate \\
\hline $\mathrm{kd}$ & $\begin{array}{c}\text { Small } \\
\text { change }\end{array}$ & $\begin{array}{c}\text { Decr- } \\
\text { ease }\end{array}$ & decrease & Small change \\
\hline
\end{tabular}

When the model of process has been known, the parameter of PID should be set. The method of adjusting the parameters of the controller is named controller tuning. Controller tuning can be achieved by model-based methods and engineering controller tuning. Empirical methods are adopted in this article.

\section{Cascade Control}

The level control of the CSTH model is somewhat more complex than the temperature control because it is affected by three factors, namely, hot water flow, cold water flow, and outlet flow. Of course, the model can be simplified, the operating for cold-water valve is set to be zero. In addition, temperature control is not necessary, so that the control of the liquid level is converted to the control of the cold water valve. The control mode is embodied in the CSTH model that the chilled water valve is controlled by the controller FC, and the setpoint of the controller FC is controlled by the controller LC. Among them, LC is called the main controller, and FC is called the sub controller. This control is called cascade control. The schematic diagram of the cascade control system is shown in Fig 3.

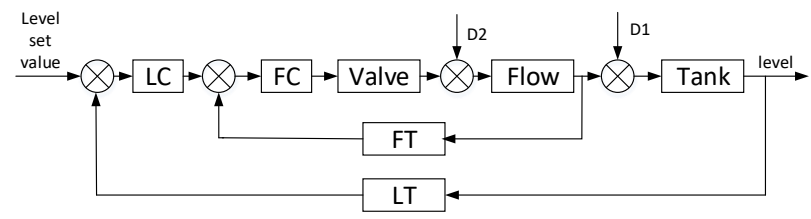

FIGURE III SCHEMAT IC DIAGRAM OF CASCADE CONTROL OF CSTH PROCESS 
Where D1 is the disturbance of the liquid level while for D2 it is the cold-water flow.

Cascade systems contain two feedback loops:

primary loop

a) regulate part of the process having slower dynamics

b) calculates setpoint for the secondary loop

secondary loop

a) regulates part of process having faster dynamics

b) maintain secondary variable at the desired target given by primary controller

The Simulink simu lation diagram of the cascade system of CSTH process is shown in Fig 4.

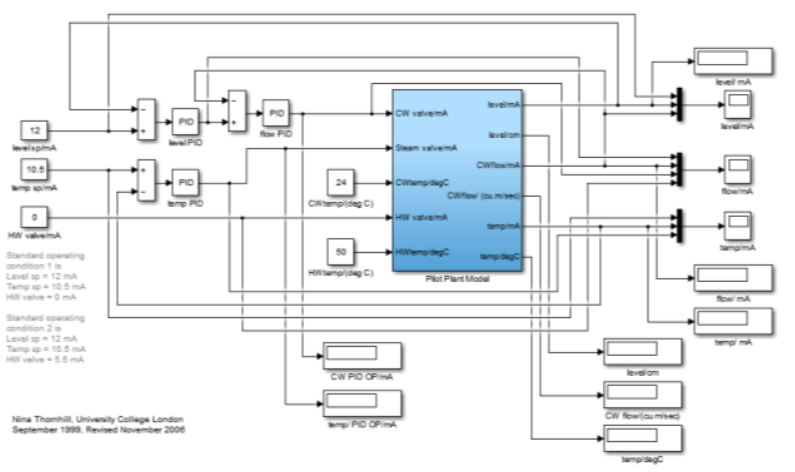

FIGURE IV SIMULINK SIMULATION DIAGRAM OF CASCADE SYSTEM OF CSTH

TABLE II. PARAMETERS VALUES FOR CASCADE CONTROL

\begin{tabular}{|c|c|c|c|}
\hline loop & \multicolumn{3}{|c|}{ Parameter } \\
\cline { 2 - 4 } & $\begin{array}{c}\text { Proportional } \\
\text { gain(kp) }\end{array}$ & $\begin{array}{c}\text { Integral } \\
\text { gain(ki) }\end{array}$ & $\begin{array}{c}\text { Derivative } \\
\text { gain(kd) }\end{array}$ \\
\hline primary loop & 2 & 0.1 & 0 \\
\hline secondary loop & 0.5 & 0.2 & 0 \\
\hline
\end{tabular}

TABLE III. PARAMETERS VALUESFOR PID CONTROL

\begin{tabular}{|c|c|c|}
\hline \multicolumn{3}{|c|}{ Parameter Values } \\
\hline $\mathrm{Kp}$ & $\mathrm{Ki}$ & $\mathrm{Kd}$ \\
\hline 3 & 0.1 & 0 \\
\hline
\end{tabular}

Table 1 and table 2 shows specifications of each PID value. Fig 5. shows the response of the liquid level and the cold-water valve position. Fig 6. shows the cold-water valve and hot-water valve position of the CSTH process. Fig 7. shows response of temperature and the position of steam valve.

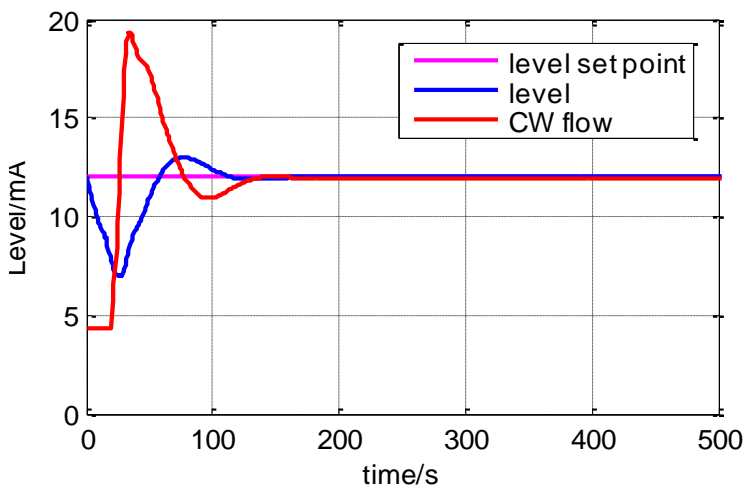

FIGURE V THE RESPONSE OF THELIQUID LEVEL AND THE COLDWATER VALVE POSITION

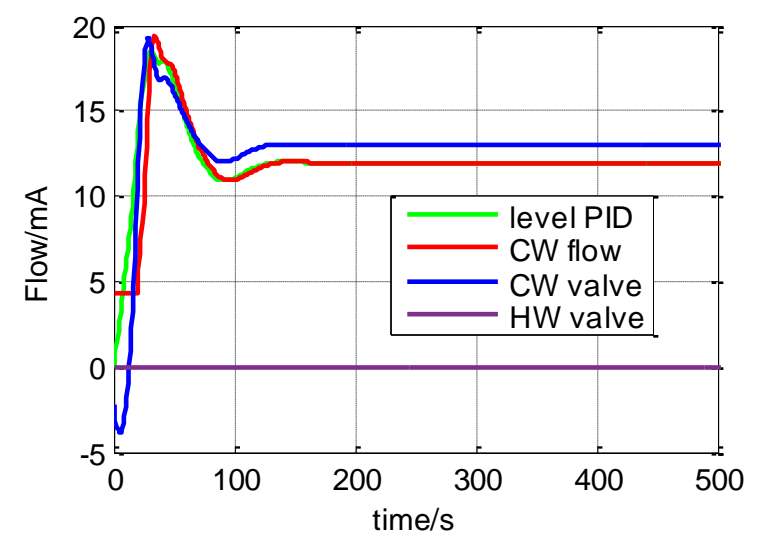

FIGURE VI THE RESPONSE OF THE COLD-WATER FLOW

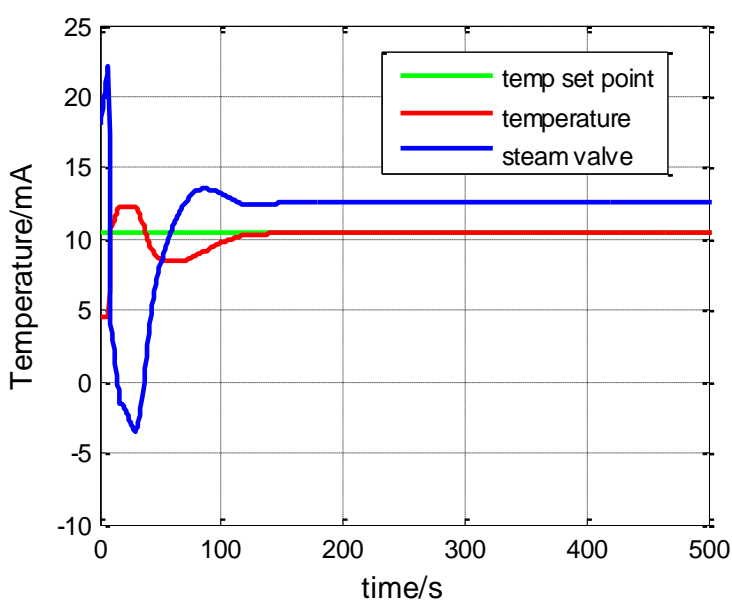

FIGURE VII THE RESPONSE OF THE TEMPERATURE

\section{CONCLUSION}

In this paper, a case-based teaching method that uses the CSTH model to teach process control is presented. The CSTH is a classic industrial process model that we can get knowledge points of process control. 


\section{REFERENCES}

[1] Seborg, D.E., T.F. Edgar, and D.A. Mellichamp. Teaching process control in the 21 st century: what has changed? in Proceedings of the 2003 American Control Conference, 2003. 2003.

[2] Johansson, K.H., et al. Teaching multivariable control using the quadruple-tank process. in Proceedings of the 38th IEEE Conference on Decision and Control (Cat. No.99CH36304). 1999.

[3] Gaurav, K. and S. Mukherjee. Design of artificial neural net work controller for continually stirred tank heater. in IECON 2012 - 38th Annual Conference on IEEE Indust rial Electronics Society. 2012.

[4] Using MATLAB for teaching transformations of random variables. in 2013 International Conference on Advances in Computing, Communications and Informatics (ICACCI). 2013.

[5] Rasouli, M., R. Weissbach, and D. Yeung. Teaching modern control theory to undergraduates using a state space model of a synchronous generat or. in 2016 IEEE Frontiers in Education Conference (FIE). 2016.

[6] Tona, P. Teaching process control with Scilab and Scicos. in 2006 American Control Conference. 2006.

[7] Zhao, Z. and G. Zhao. The research of teaching methodology on operating system process control. in 2011 6th International Conference on Computer Science \& Education (ICCSE). 2011.

[8] Guarnizo, J.G. and J. Avendano. Liquid level system as a pedagogical tool to teach fuzzy control. in 2017 International Conference on Electronics, Communications and Computers (CONIELECOMP). 2017.

[9] Nazaruddin, Y.Y. and A. Siahaan. Teaching intelligent control using a laboratory-scaled process mini-plant. in 2017 IEEE 26th International Symposium on Industrial Electronics (ISIE). 2017.

[10] Thornhill, N.F., S.C. Patwardhan, and S.L. Shah, A continuous stirred tank heater simulation model with applications. Journal of Process Control,2008. 18(3): p. 347-360.

[11] Sehgal, S. and V. Acharya. Design of PI controller for Continuous Stirred Tank Heater process. in Electrical, Electronics and Computer Science (SCEECS), 2014 IEEE Students' Conference on. 2014. 